\title{
Hurdle Aerobic Exercise Increases Angiogenesis and Neuroplasticity in the Hippocampus and Improves the Spatial Memory Ability of Middle-aged Mice
}

\author{
Irfannuddin Irfannuddin ${ }^{1 *}$, Minarma Siagian², Sri Jusman ${ }^{3}$, Jan Purba $^{4}$, Ermita Ilyas $^{2}$, Nurhadi Ibrahim² \\ ${ }^{1}$ Department of Physiology, Faculty of Medicine, Universitas Sriwijaya, Palembang, Indonesia; ${ }^{2}$ Department of Physiology, \\ Faculty of Medicine, Universitas Indonesia, Depok, Indonesia; ${ }^{3}$ Department of Biochemistry and Molecular Biology, Faculty \\ of Medicine, Universitas Indonesia, Depok, Indonesia; ${ }^{4}$ Department of Neurology, Faculty of Medicine, Universitas Indonesia, \\ Depok, Indonesia
}

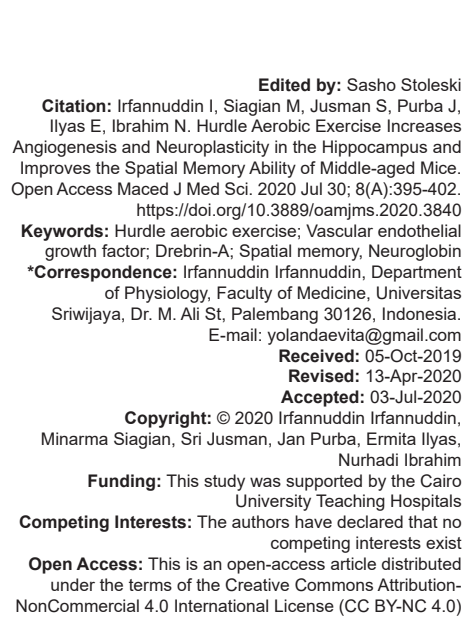

\begin{abstract}
BACKGROUND: Complex aerobic exercise is believed to induce positive effects on neuron structure and cognitive function. Long-term and continual cognitive stimulation increases neuroplasticity by stimulating the synthesis of neuronal growth proteins and the formation of new synapses. Exercise also increases the ability of neurons to survive and improves brain vascularization. Further investigations should be conducted to explore what types of aerobic exercise are beneficial for cognitive function.
\end{abstract}

AIM: This study investigated the effects of hurdle aerobic exercise on developmentally regulated brain protein-A (Drebrin-A) as a neuroplasticity indicator, and on vascular endothelial growth factor (VEGF) as an angiogenesis marker in the hippocampus.

METHODS: This study was an experimental study with post-test only control group design. Thirty-three adult mice were divided into control, hurdle aerobic runner (HAR), and plain aerobic runner (PAR) groups ( $n=11$ for each group). Fiberglass running wheels were originally designed and modified to assemble hurdles inside with adjustable speed. Speed adaptation was intended to achieve aerobic intensity. The experiment was performed 5 times a week for 8 weeks. The Morris water maze test (MWMT) was used to assess spatial memory ability. One day after the las running exercise and final MWMT, the mice were sacrificed and the right side of the hippocampus was obtained for Drebrin-A analysis by enzyme-linked immunosorbent assay (ELISA). The entire right side brain tissue after hippocampus was removed then used for the neuroglobin ELISA assay. To analyze VEGF expression and calculation of blood vessel, the left side of the brain was prepared for hematoxylin eosin and immunohistochemistry staining. To assess the effect of exercise on vascular widening, the analysis of the slides was performed by calculating the percentage of blood vessels with diameters more than $15 \mu \mathrm{m}$. One-way ANOVA and Fisher's least significant difference test was used for statistical analysis.

RESULTS: There was a significant difference in the levels of Drebrin-A between the HAR and PAR groups. Both exercise groups had higher levels of Drebrin-A than the control group. HAR and PAR groups exhibited significantly higher percentages of blood vessels expressing VEGF in hippocampus compared to control. HAR and PAR groups had the higher percentages of larger vessels compare to control. There was no significant difference of neuroglobin levels among the three groups. Both the HAR and PAR groups exhibited better spatial memory than the contro group.

CONCLUSION: Both aerobic exercises induced positive effects on brain angiogenesis, while the intensity of aerobic exercises did not result in high hypoxic stress in the brain.

\section{Introduction}

Exercise as a non-pharmacological intervention is highly recommended against cognitive degeneration [1], [2], [3]. Regular exercise is a type of long-term stimulation that improves cognitive function. Regular exercise has been proven to improve memory retention, memory acquisition, and learning ability [2], [3]. Exercise stimulates neuronal growth factors, even when the activity is begun during adulthood [4]. Long-term and continual cognitive stimulation increases neuroplasticity by stimulating the synthesis of neuronal growth proteins and the formation of new synapses [5]. Exercise also increases the ability of neurons to survive and improves brain vascularization [6], [7].

The previous studies have detailed the effects of running, regarded as a simple regular exercise, on neurogenesis, and angiogenesis in the hippocampus [2], [4]. Humans and mammals engage in running as a regular activity, beginning at early ages. Running has become an automatic movement that relies on simple thinking [8]. Aerobic exercise in the form simple movements was observed only has small benefit to building cognitive [9]. Further investigations should be conducted to explore what types of aerobic exercise are 
beneficial for cognitive function. In human, persons who often play structured games were able to adapt better than persons who practice in the form of simple exercise such as a treadmill or stationary bike [10].

Information regarding the effects of complex aerobic exercise on brain is necessary to determine the best type of exercise for cognitive functions. However, this information remains limited. We hypothesized that a more complex aerobic exercise has better effects to increase the formation of neurogenesis proteins in neuron tissue, and increased cognitive functions. In experiments involving animals with limited cognitive capacities, a complex movements exercise that can be developed include running with additional simple hurdles. The animal runs on tracks that require various additional movements, such as jumping, curving, and bowing.

We conducted this study using aged mice, where the effects of aerobic hurdle running exercise on Drebrin-A and vascular endothelial growth factor (VEGF), which play a dominant role in angiogenesis and neuroplasticity in the hippocampus tissues, were measured. The number of blood vessels and percentage of larger blood vessels (diameters $>15 \mu \mathrm{m}$ ) were manually counted to analyze whether the exercise was followed by the formation of new blood vessels and the changing of blood vessel's diameter. The spatial memory ability of these mice was also measured using a well-known method called the Morris water maze test (MWMT) [11]. In addition, the effects of this exercise on brain neuroglobin levels, as an adaptation of oxidative stress, were also studied.

\section{Materials and Methods}

\section{Animal preparation}

This study was an experimental study with post-test only control group design. Thirty-three adult (10 months of age) male mice (Mus musculus CBSSwiss strain) were housed and divided into control, hurdle aerobic runner (HAR), and plain aerobic runner (PAR) groups ( $n=11$ for each group). This study had been in accordance to European Guidelines on Laboratory Animal Care. The mice were maintained under a 12:12 h dark-light cycle in a $3 \times 4 \mathrm{~m}^{2}$ room maintained at $23^{\circ} \mathrm{C}$ with an air conditioner. They were housed in $30 \times 30 \times 50 \mathrm{~cm}^{3}$ cages (5-6 mice per cage) and had free access to standard pellets and plain water provided ad libitum. Sawdust was added to the cages, cleaned, and replaced every 2 days.

\section{Running wheel}

Fiberglass running wheels (perimeter $156 \mathrm{~cm}$ ) were originally designed and modified to assemble hurdles inside with adjustable speed. Two hurdles were placed at opposite sides of the wheel, such that the mice were required to pass through an obstacle every $78 \mathrm{~cm}$. There were three types of hurdles, which were exchanged in the wheel every 3 days. The hurdles required the mice to jump, duck, or maneuver right or left while running. The running wheels had four tracks; each mouse ran on separate track along the exercise.

\section{Speed adaptation}

Speed adaptation for 2 weeks was intended to achieve aerobic intensity. During the $1^{\text {st }}$ week, two groups of running mice (HAR and PAR) were introduced to the running wheel for $20 \mathrm{~min}$ a day. The running wheel was rotated at a speed of $2-3 \mathrm{~m} / \mathrm{min}$ and increased slowly. At the end of the $1^{\text {st }}$ week, the mice were able to run at a speed of 8-10 $\mathrm{m} / \mathrm{min}$. During the $2^{\text {nd }}$ week, the adaptation stage was followed by an optimization stage. Optimization specifically targeted the HAR groups to identify the optimal speed that could be achieved by the mice while passing through the obstacles.

After optimization for 7 days, the HAR mice were able to run optimally at a speed of $10-11 \mathrm{~m} / \mathrm{min}$. At these speeds, the mice had to run through barriers every $4.5 \mathrm{~s}$. The mice were subjected to speeds above $11 \mathrm{~m} / \mathrm{min}$ several times but failed. Therefore, the speed of $10 \mathrm{~m} / \mathrm{min}$ was used throughout the experiment to ensure that all of mice could run smoothly through barriers at aerobic intensity. For mice, running at $10 \mathrm{~m} / \mathrm{min}$ is $60 \%$ of the critical speed for reaching their anaerobic threshold [12]. This indicated that the velocity was optimal for light intensity aerobic exercise. During the adaptation and optimization phases of HAR group, the running speed for the PAR group was always equal to the speed of the HAR group.

\section{Running experiment (8 weeks)}

The HAR group ran for $40 \mathrm{~min}$. The exercise began with a warm-up and ended with a cooling down for $5 \mathrm{~min}$ at a speed of $6 \mathrm{~m} / \mathrm{min}$. The mice ran of core intensity at a speed of $10 \mathrm{~m} / \mathrm{min}$. The mice were required to run while making challenging movements to avoid obstacles. Every $10 \mathrm{~min}$, the wheel was slowed to $6 \mathrm{~m} / \mathrm{min}$ for $1 \mathrm{~min}$, then reaccelerated to a speed of $10 \mathrm{~m} / \mathrm{min}$. Changing the speed caused the mice to decrease and increase their speed several times. Mice ran at vary running speed to enrich biomechanics stimulation. The experiment was performed 5 times a week for 8 weeks. The PAR group ran at the same time as the HAR group at a constant speed of $10 \mathrm{~m} / \mathrm{min}$, but without obstacles. For the control group, the animals were not subjected to the aerobic exercise and were placed in the animal enclosures during the experiment. 


\section{MWMT}

About $28 \mathrm{~L}$ of plain water was filled into the cylinder fiber diameter of $60 \mathrm{~cm}$ so that the water level reached a depth of $10 \mathrm{~cm}$ from the bottom. Dark food coloring was added to the water. Dark footing was hidden placed at a fixed position under $1 \mathrm{~cm}$ from water surface. For adaptation, mice were let to swim in cylinder for $1 \mathrm{~min}$, once in every 2 days for 3 weeks. MWMT procedure was performed for 5 days. This procedure was carried out in the past week of physical exercise, or starting 5 days before decapitation. Mice were released in the cylinder from the starting place. Mice were allowed to swim in the cylinder, and if after $30 \mathrm{~s}$ did not find a flat footing, mice were placed on a flat footing. The procedure was carried out 2 times. The third experiment was test procedure. Mice were released into the water from early position and left to find a flat footing. Latent time of test procedure was noted [11].

\section{(ELISA)}

\section{Enzyme-linked immunosorbent assay}

One day after the last running exercise and final MWMT, the mice were sacrificed through dislocation of their heads by stretching cervical bones from the thoracic vertebrae. The head was decapitated, and the brain removed and placed on a cool flat iron slab placed on ice in $0.01 \mathrm{M}$ liquid PBS. The right side of the hippocampus was taken for Drebrin-A analysis. The tissue was excised based on the literature reports. The hippocampus is located just below the parietal cortex. The parietal cortex was removed using forceps, and hippocampus tissue $-1 \mathrm{~mm}$ area to $-4 \mathrm{~mm}$ behind the bregma was excised. Hippocampus was then weighed with ultra-microbalance (Shimadzu scale ${ }^{\circledR}$ ).

Tissue homogenization and sandwich ELISA for Drebrin-A were guided using a manual mouse Drebrin (DBN1) ELISA kit (code number MBS918641, MyBioSource.com ${ }^{\circledR}$ ). Brain tissue was rinsed in $0.01 \mathrm{M}$ PBS at a ratio of $0.1 \mathrm{ml}$ of PBS to $10 \mathrm{mg}$ of tissue. The tissue was homogenized and stored overnight at $-20^{\circ} \mathrm{C}$. Two freeze-thaw cycles were performed to break the cell membranes. The homogenates were centrifuged for $5 \mathrm{~min}$ at $5000 \times \mathrm{g}, 4^{\circ} \mathrm{C}$. The supernatant was taken and assayed.

The entire right side brain tissue after hippocampus was removed then used for the neuroglobin ELISA assay. Tissue homogenization and sandwich ELISA analysis were guided using a manual mouse neuroglobin (NGB) ELISA kit (code MBS266301 MyBioSource.com $\left.{ }^{\circledR}\right)$. The brain tissue was sliced and rinsed in $0.01 \mathrm{M}$ PBS. Protein extraction reagent $(\mathrm{NaCl}$ $0.86 \%$ ) at a proportion of $1 \mathrm{ml}$ for $100 \mathrm{mg}$ of tissue was added. The tissue was homogenized at a cool temperature. After blending, the homogenates were centrifuged for $5 \mathrm{~min}$ at $5000 \times \mathrm{g}$ at a temperature of $4^{\circ} \mathrm{C}$. The supernatant was taken for assay. Drebrin-A and neuroglobin levels were measured by optical density reader (V-max ${ }^{\circledR}$ multiple reader) at $450 \mathrm{~nm}$. The concentration was recalculated according to tissue weight.

\section{Histology-HE staining and immunohistochemistry (IHC)}

To analyze VEGF expression and calculation of blood vessel, the left side of the brain was prepared for hematoxylin eosin (HE) and IHC staining. Brain tissue was immediately immersed in $10 \%$ formaldehyde solution for $24 \mathrm{~h}$ at room temperature. The tissue then was dehydrated using serial steps of alcohol (80\%, $90 \%$, and $100 \%$ ) by automatic tissue processing machine (Sakura $\left.{ }^{\circledR}\right)$ followed by immersion in xylene twice and then in liquid paraffin 3 times. After soaking in hot paraffin, the tissue was then prepared for embedding in paraffin blocks. Hippocampal tissue sections were cut from -2 to $-3 \mathrm{~mm}$ behind bregma with $10 \mu \mathrm{m}$ thickness. Every section was stained with $\mathrm{HE}$ staining then observed under light microscope to subjectively select the three best sections of each brain slices for IHC and three best sections of each mouse brain for calculation of blood vessels based on HE staining.

For IHC examination, the sections were mounted on polylysine-coated slides and dried followed by the antigen retrieval. After antigen retrieval the tissues then rinsed in PBS $0.1 \mathrm{M}, 3$ times for 5 min each and incubated with peroxidase blocking solution for $20 \mathrm{~min}$ at room temperature. The tissues were washed 3 times (5 min each) in PBS0.1 M, then incubated with mouse monoclonal antibody anti-VEGF (1:200: sc-7269 Santa Cruz Biotechnology, Inc.) for $1 \mathrm{~h}$ at room temperature. Following washing with PBS $0.1 \mathrm{M} 3$ times, the tissues then incubated with Novolink ${ }^{\mathrm{TM}}$ polymer detection system (Leica Biosystems Newcastle Ltd, UK) for 20 min at room temperature. Next, the slides were incubated with post primary: Rabbit anti-mouse IgG in 10\% (v/v) animal serum in Tris-buffered saline/0.09\% Proclin ${ }^{\mathrm{TM}}$ 950 for $30 \mathrm{~min}$ in the moisture chamber. The tissues then washed in PBS $0.1 \mathrm{M} 2$ times for $5 \mathrm{~min}$ each. Afterward, the slides were incubated with Poly-HRP-IgG Novolink $^{\mathrm{TM}}$ polymer anti-rabbit in $10 \%$ of animal serum in a $0.09 \%$ saline tube Proclin ${ }^{\mathrm{TM}} 950$ for $30 \mathrm{~min}$ at room temperature. The tissues were washed in PBS $0.1 \mathrm{M}$, $2 \times 5$ min. Peroxidase activity was developed with $D A B$ Chromogen drip, $1.74 \% \mathrm{w} / \mathrm{v}$ 3,3'-diaminobenzidine + Novolink Dab substrate buffer for $5 \mathrm{~min}$, then washed 3 times with PBS $0.1 \mathrm{M}$ for $5 \mathrm{~min}$ each. The slides then were counter stained with $0.1 \%$ hematoxylin for $5 \mathrm{~min}$ then rinsed with running tap water for $5 \mathrm{~min}$. The tissues were dehydrated in ascending alcohols ranging from $70 \%, 80 \%$, and $90 \%$ and absolute $(100 \%)$ alcohols, each for $5 \mathrm{~min}$. The slides then cleared with xylene 2 $\times 5$ min and covered with mounting medium and finally with glass cover slips. 
Sections were visualized and photographed using an Olympus ${ }^{\circledR}$ BX51 bioptic microscope. Each vessel in the entire hippocampus region was traced and counted, started form dorsal hippocampus, the subiculum then to cornu amonis (CA) 1, CA2, turned to ventral in the CA3 region, to the dentate gyrus. All hippocampus regions were identified $\times 10$. All regions of interest in the whole area of hippocampus were captured at higher magnification $(\times 40)$ to calculate the total number of vessel, number of vessels that express VEGF in its endothelium, and number of vessels with $>15$ $\mu \mathrm{m}$ (larger) in diameter. Blood vessels were calculated blindly using Image-J software by two histologists. The final counts were determined from the mean values of both histologists' calculations. The number of VEGF positive vessels was calculated in the percentage from total number of blood vessels. Blood vessels with $>15 \mu \mathrm{m}$ in diameter were determined by comparing to an imaginary circle (diameter $15 \mu \mathrm{m}$ ) drawn in the Image-J software. Larger diameter vascular percentage was calculated as the number vessels with $>15 \mu \mathrm{m}$ in diameter, divided by total number of blood vessels in the all hippocampus area.

\section{Statistical analysis}

A one-way ANOVA test was used to analyze differences in the average levels of the three groups of mice, as all of the numeric data exhibited normality and homogeneity in the variance with $p>0.05$. For further analyses, a Fisher's least significant difference (LSD) test was used to assess the degree of difference among each group. For MWMT, a one-way ANOVA test was used to analyze the differences of MWMT result on $5^{\text {th }}$ day regarding to $1^{\text {st }}$ day. All of the statistical calculations were performed using SPSS 13.0 for Windows.

\section{Ethical approval}

The research protocol was carefully reviewed and approved by The Health Research Ethics Committee of the Faculty of Medicine, Universitas Indonesia.

\section{Results}

Drebrin-A levels were measured to assess the activity of neuroplasticity in hippocampus. A oneway ANOVA test showed significant differences. This result indicated that aerobic exercise had a significant effect on neuroplasticity. The post hoc Fisher LSD test showed that there was a significant difference in the levels of Drebrin-A between the HAR and PAR groups. This result revealed that, in the hippocampus, hurdle aerobic running stimulated neuroplasticity better than plain aerobic running. Both exercise groups had higher levels of Drebrin-A than the control group (all $p<0.05$ ) (Figure 1a). Thus, all types of aerobic exercise stimulate neuroplasticity better than no exercise. VEGF expression was calculated on the endothelial walls of blood vessels (Figure 1b). The number of blood vessels was manually counted to analyze whether the increased expression of VEGF was followed by the formation of new blood vessels (Figure 1c). There was no difference in the number of blood vessels among the three groups of mice. The rate of angiogenesis was measured based on the percentage of blood vessels that showed expression of VEGF divided by total numbers of vessels in the all hippocampus regions (Figure 2).

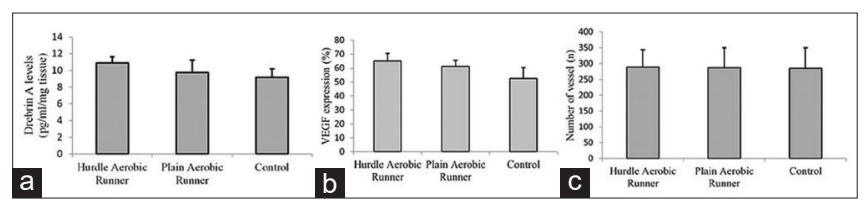

Figure 1: (a) Drebrin-A levels (mean $\pm S D$ ) in hippocampus tissue. $A$ one-way between subjects ANOVA test: $\left(F_{230}=6.92, p<0.01\right)$. The post hoc Fisher least significant difference (LSD) test between hurdle aerobic runner (HAR) and plain aerobic runner (PAR) was significant $(p<0.05)$, between HAR and control was significant $(p<0.01)$ and between PAR and control was significant $(p<0.05)$. (b) The mean percentage $( \pm S D)$ of blood vessels that showed expression of vascular endothelial growth factor in vascular endothelial divided by total vessels number in hippocampus. A one-way between subjects ANOVA test was significant: $\left(F_{2,30}=12.68, p<0.001\right)$. The post hoc Fisher LSD test between HAR and PAR was not significant $(p>0.05)$, between HAR and control was significant $(p<0.001)$, and between $P A R$ and control was also significant $(p<0.001)$. (c) Number of vessel (mean $\pm S D)$ in all region of hippocampus. A one-way between subjects ANOVA test was not significant $\left(F_{2,30}=0.017, p>0.05\right)$. The post hoc Fisher LSD test was not analyzed

HAR and PAR groups exhibited significantly higher percentages of blood vessels expressing VEGF in hippocampus compared to control (Figure 1b). The post hoc Fisher LSD test showed that the HAR and PAR groups had significant higher percentages of blood vessels expressing VEGF compared to the control. However, there was no significant difference of VEGF expression between the HAR and PAR groups. This result suggests that both aerobic exercises stimulated

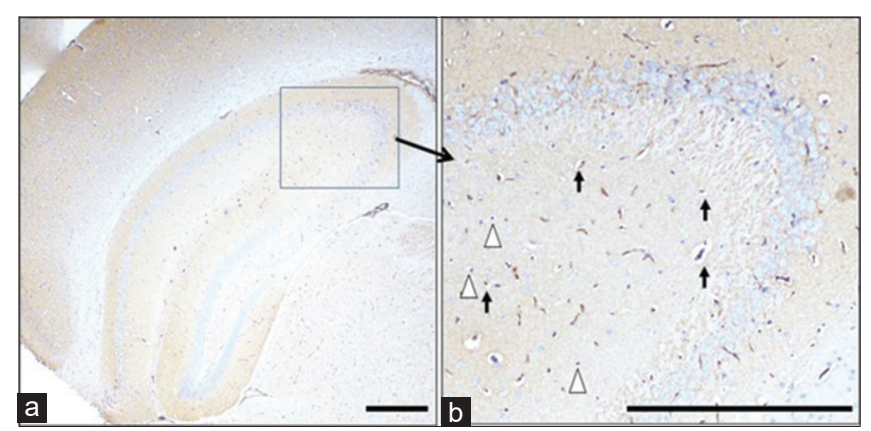

Figure 2: Vascular endothelial growth factor (VEGF) expressions in the vessels endothelial of hippocampus. (a) Immunohistochemistry slides of the hippocampus $(\times 10)$ labeled with the primary antibody anti-VEGF (C-1): sc-7269 (Santa Cruz Biotechnology production Inc.) and secondary antibody (Novolink ${ }^{\mathrm{TM}}$ Polymer) poly anti-rabbit lgGHRP. (b) Black arrow shows vascular endothelial expressed VEGF, and white triangle indicates blood vessels that are not expressing VEGF (×40). Scale bar: $200 \mu \mathrm{m}$. 
angiogenesis while control did not. However, the rate of angiogenesis in hurdle aerobic exercise was not significant different compared to the effect of plain aerobic exercise.

To assess the effect of exercise on vascular widening, the analysis of the slides was performed by calculating the percentage of blood vessels with diameters more than $15 \mu \mathrm{m}$ (Figure 3 ).

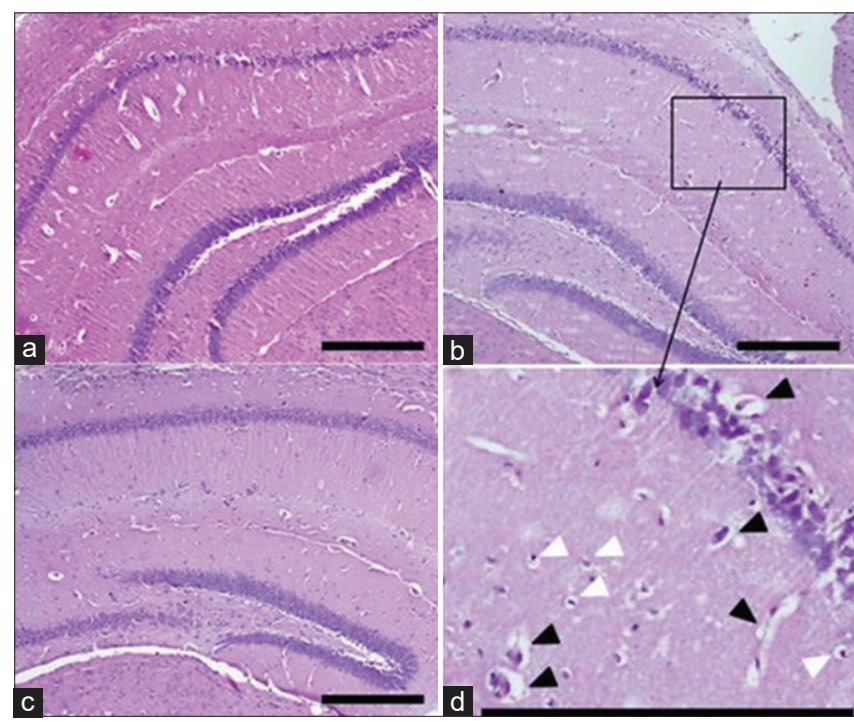

Figure 3: Variation in diameter of blood vessels in the hippocampus. The proportion of large-diameter blood vessels was greater in the hurdles aerobic (a) and plain aerobic (b) exercise groups compared to the control group (c) blood vessel diameters $>15 \mu \mathrm{m}$ are indicated by black triangles, and vessels with diameters $<15 \mu \mathrm{m}$ are marked white triangles (d) scale bars: $200 \mu \mathrm{m}$

The percentage of blood vessels with diameters $>15 \mu \mathrm{m}$ divided by total blood vessels in the hippocampus was calculated (Figure 4a). HAR and PAR groups had the higher percentages of larger vessels compare to control. The post hoc Fisher LSD test showed that there were significant differences between the HAR group and the control group, and between the PAR and control groups. However, there was no significant difference between the HAR and PAR groups. Aerobic exercise was able to dilate the blood vessels in the hippocampus, but two types of aerobic exercise had a no different effect on blood vessel diameter. The neuroglobin levels of brain tissue were measured to analyze brain tissue adaptation to higher $\mathrm{O}_{2}$ requirements. There was no significant difference of NGB levels among the three groups (Figure 4b).

In this study, a well-known method MWMT was conducted for assessing the cognitive abilities of mice. This method aimed to quantify the ability of spatial memory. Spatial memory was measured based on the time needed to find the flat footing hidden under water [11]. The ANOVA test showed that there was a significant effect of aerobic exercise on MWMT test results on the $5^{\text {th }}$ day after controlling for MWMT test results on the $1^{\text {st }}$ day.

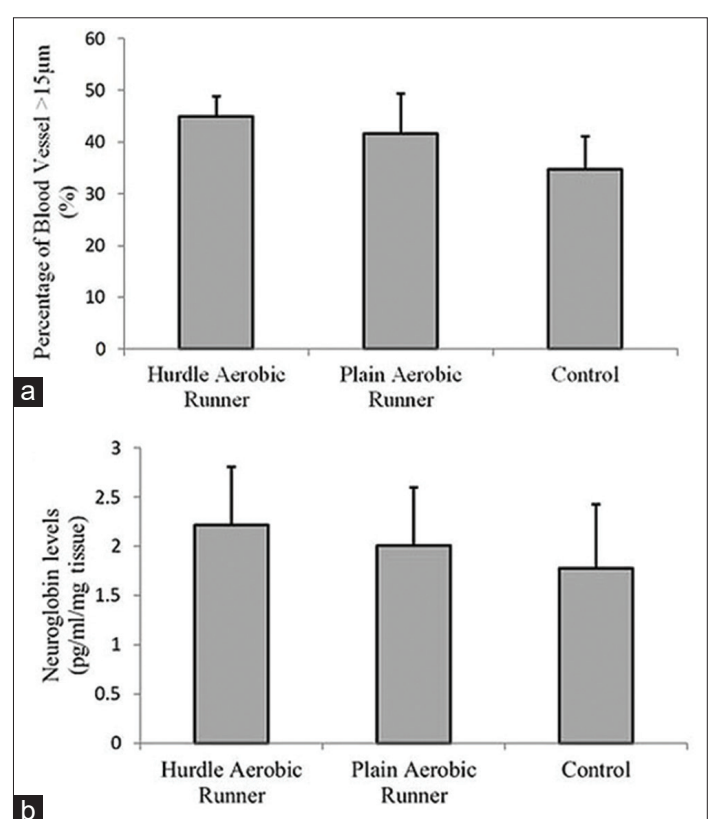

Figure 4: (a) The percentage of blood vessels (mean $\pm S D$ ) with diameters $>15 \mu \mathrm{m}$ divided by total blood vessels in the hippocampus. A one-way between subjects ANOVA test was significant $\left(F_{230}=5.40\right.$ $p<0.05)$. The post hoc Fisher least significant difference (LSD) test between hurdle aerobic runner (HAR) and plain aerobic runner (PAR) group was not significant ( $p>0.05)$, between HAR and control was significant $(p<0.001)$, and between PAR and control was significant $(p<0.05)$. (b) Neuroglobin levels in the brain tissue. A one-way ANOVA test between subjects was not significant $\left(F_{2,30}=1.43\right.$, $p>0.05)$. The post hoc Fisher LSD test was not analyzed due to ANOVA test was not significant

The post hoc Fisher LSD test revealed significant differences between HAR and PAR groups in latency time, and both the HAR and PAR groups exhibited better spatial memory than the control group (Figure 5). This indicated that hurdle aerobic running

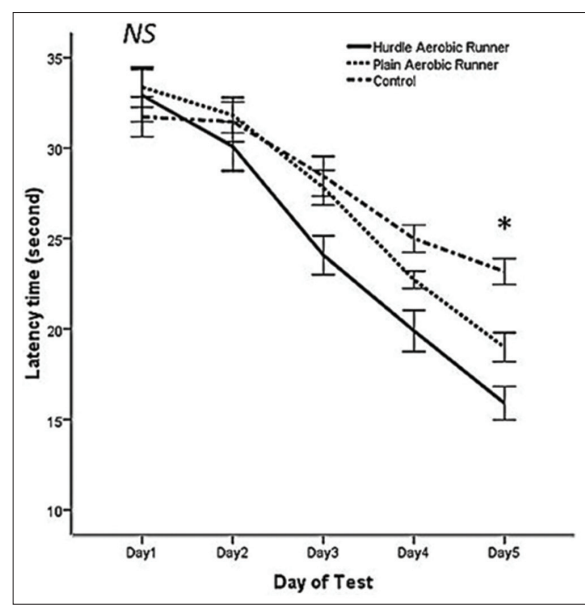

Figure 5: Time needed for the mice to reach footing (mean \pm SE). On day 1, all of three groups showed equivalent latency time. Hurdle aerobic runner (HAR) (32.91 $\pm 4.82 \mathrm{~s})$, plain aerobic runner (PAR) $(33.36 \pm 3.67 \mathrm{~s})$, and control $(31.73 \pm 3.69 \mathrm{~s})$. The one-way ANOVA test showed not significant (NS): $\left(F_{2,30}=0.468, p>0.05\right)$. On the $5^{\text {th }}$ day, latency time of HAR group (15.91 $\pm 3.01 \mathrm{~s})$ was faster than PAR group (19.00 \pm 2.68$)$, and the longest time was the control group $(23.18 \pm 2.40 \mathrm{~s})$. The one-way ANOVA test showed significant (*): $\left(F_{2,30}=33.73, p<0.001\right)$. The post hoc Fisher $L S D$ test for $5^{\text {th }}$ day: HAR versus PAR, $p<0.05$; HAR versus control, $p<0.001$; PAR versus control, $p<0.01$ 
increases spatial memory ability better than plain aerobic running. Both exercise groups improve spatial memory ability better than no exercise.

\section{Discussion}

This study investigated whether a complex aerobic exercise (HAR group) induced a different effect on neuroplasticity than in simple aerobic exercise (PAR group) and control. Neuroplasticity is the inherent capacity of nerve tissue to form new interneuronal connections or synapses (synaptogenesis) or to replace nonfunctional neurons in the brain with new neurons (neurogenesis) [13]. The changing shape of synapses, which plays a pivotal role for synaptic plasticity, is governed by actin resided in dendritic spines. Dendritic spine elongation depends on dynamic filamentous actin (F-actin) polymerization [14]. Drebrin is an actinbinding protein that changes the helical pitch of F-actin. In adult's brain, Drebrin-A plays two pivotal roles in structure-based synaptogenesis by modulating F-actin properties. First, following long-term potentiation (LTP) stimulation, Drebrin-A in form of Drebrin A-decorated stable F-actin, will exodus. The exodus of Drebrin-A reduces the stable $\mathrm{F}$-actin core in dendritic spine, followed by monomeric actin (G-actin) refilling in the spine to facilitate actin nucleation and polymerization of dynamic F-actin to elongate the spine. Second, Drebrin-A has the rule of reconstructing stable actin. Drebrin A-decorated F-actin reconstructed in dendritic spines to maintain of enlarged spine morphology. Inhibition of Drebrin-A expression results in a delay of synapse formation and inhibition of postsynaptic protein accumulation. Meanwhile, overexpression of Drebrin-A induces spine elongation in mature neurons [15], [16].

Both types of aerobic exercise increased neuroplasticity in the hippocampus, and more complex running (HAR group) had better effect than PAR group. Exercise with hurdles requires the animal to perform more complex movements that involves more synaptic connectivity and higher cognitive abilities. It is thought that synaptic growth will continue to increase if there is a combination of learning stimulation and increment of energy/O $/ \mathrm{O}_{2}$ supply [17]. Central motor neuron plasticity relies on the environmental enrichment and forced physical activity. These activities have been upregulated endogenous factors involved in plasticity, even in injured animal [18].

The complex exercise also gave better effects of cognitive performance. The MWMT results showed that the exercise group performed significantly better than the control group, in which the HAR group exhibited the highest cognitive performance. More body movements during exercise stimulate more complex activities of synaptic neurotransmitters that are used for coordination of sensory perceptions, sensory-motoric integrations, and motoric activities [19]. Behavioral memory is mediated by plasticity in the synaptic connections between neuron that participate in particular behavior [20]. Persistent stimulation or LTP stimulates plasticity in pre- and post-synaptic, synthesizing proteins that alter membrane structure of neurons, forming new Synaptics and building memory formation [21].

This study showed that VEGF expression was more largely available in the exercise groups (HAR and PAR). Exercise improves brain circulation by increasing oxygen demand and stimulating the activity of neurons [17]. VEGF production accelerates during the body is in hypoxia [22]. Exercise does increased $\mathrm{O}_{2}$ and nutrition demands resulting adaptation in same pathway with hypoxia [23]. Increased $\mathrm{O}_{2}$ demand stimulates the production of various gene transcriptions that are oxygen-regulated, such as hypoxia inducible factor (HIF), and VEGF is a major transcriptional target for HIF-1 [23], [24], [25].

Based on the findings, exercise did not increase the number of blood vessels. However, the percentages of vascular vasodilatation or larger diameter $(>15 \mu \mathrm{m})$ vessels was greater in the exercise groups. Exercise increases flow velocity through a vessel and leads to an endothelial-dependent and nitric oxide (NO)-dependent enlargement of the vessel to stimulate angiogenesis. The angiogenic growth factor VEGF appears to be an important element in angiogenesis. [26]. At the early stages of angiogenesis, production of VEGF, lead to dilatation and increased permeability of blood vessels. Vasodilatation is needed in endothelial cell budding. Vessel enlargement loses the interendothelial contacts and leakage from preexisting vessels [27]. VEGF stimulates the production of $\mathrm{NO}$, and it is also the main factor responsible for vasodilatation [27], [28]. VEGF also facilitates further steps of angiogenesis, where it leads to degradation of extracellular matrix, endothelial migrations and proliferation, and synthesis of various enzymes and growth factors to build new vascular that was not investigated in this study. Further studies are needed to investigate the effects of exercise on the whole stages of angiogenesis, including the form of new vessels. Histological evidence was not supported for running induced changes in vasculature in mice [29]. Various studies have revealed that aerobic exercise increases vascular density in the brain. Vascular density is the proportion of the brain area covered by blood vessels. Vascular density is determined by the number of vessels and vascular diameter [17, [30], [31].

The increased levels of NGB in this study were not significant and differed from a study in which NGB expression was significantly increased during severe oxidative stress, such as severe hypoxia or ischemia in the brain [32]. The slight increase in NGB could be due to mice ran at a speed of $10 \mathrm{~m} / \mathrm{min}$, which corresponds to light aerobic exercise and, thus, did not 
cause severe oxidative stress. In hypoxia or ischemia, the expression of NGB increases to protect neurons. NGB acts as a scavenger of free radicals which damage cells [24], [33]. NGB also plays a strong role in maintaining cell survival by securing mitochondria and preventing apoptosis by inhibiting the opening of mitochondrial permeability transition pores and inhibiting caspase pathways [34].

This study revealed beneficial effects of light intensity aerobic exercise training that improves brain neuroplasticity. The results are consistent with the results of Lou et al. in young Sprague-Dawley rats, of which it showed that neurogenesis occurred more frequently in the group where the rats ran at a light intensity compared to the moderate intensity, high intensity, or control groups [4]. A 7 days walked with speed $12-15 \mathrm{~m} / \mathrm{min}$ on rats was sufficient to cause an increase of BDNF protein expression and TrkB $^{\mathrm{FL}}$ in neuron of spinal cord [18]. In another study, light exercise was shown to improve the ability of nerve cells to survive. Aerobic exercise on a treadmill in transgenic mice Tg-NSE/hPS2m who suffered Alzheimer's disease suppressed various inflammatory proteins triggers, and stimulated the synthesis of antioxidants [6].

Future studies are needed to identify the type of exercise that is suitable for improving and maintaining cognitive function. Cognitive degeneration is linked with the same risk factors as cardiovascular degeneration. Hypertension, dyslipidemia, and diabetes have been shown to have an impact on early dementia disorders. Therefore, aerobic exercise aimed to reduce cardiovascular disease risk factors is also recommended to inhibit the progression of cognitive degeneration. Research in the elderly has shown that those with better cardiorespiratory fitness have a larger hippocampal volume and better spatial memory [35]. Aerobic exercise combined with locomotor stimulation could be the most suitable type of exercise to improve cognitive function. The gymnastic aerobic exercise, with fun and imaginative movements, has been proven to increase BDNF level among children [36]. Limitation of this study was the post-test only control group design, which MWMT was not assessed before the experiment. Further study could explore more on this topic with improved methods.

\section{Conclusions}

In animal experimental studies, complex aerobic exercise was better than simple aerobic exercise for improving the structure and function of neurons. Further research is needed to determine whether complex aerobic exercise yields different benefits than simple aerobic exercise on the cognitive structure and function in humans.

\section{References}

1. Petersen RC, Stevens JC, Ganguli M, Tangalos EG Cummings JL, Dekosky ST. Practice parameter: Early detection of dementia and mild cognitive impairment (evidence-based review): Report of the quality standards subcommittee of the American academy of neurology. Neurology. 2001;56(9):113342. https://doi.org/10.1212/wnl.56.9.1133

PMid:11342677

2. Van-Der Borght $K$, Havekes $\mathrm{R}$, Bos $\mathrm{T}$, Eggen BJ, Van Der Zee EA. Exercise improves memory acquisition and retrieval in Y-maze task: Relationship with hippocampal neurogenesis. Behav Neurosci. 2007;121(2):234-44. https://doi. org/10.1037/0735-7044.121.2.324

PMid:17469921

3. Erickson KI, Voss MW, Prakash RS, Basak C, Szabo A ChaddockL, etal. Exercise training increases size of hippocampus and improves memory. PNAS. 2011;108(7):3017-22. PMid:21282661

4. Lou SJ, Liua JY, Chang H, Chen PJ. Hippocampal neurogenesis and gene expression depend on exercise intensity in juvenile rats. Brain Res. 2008;1210:48-55. https://doi.org/10.1016/j. brainres.2008.02.080 PMid:18423578

5. Kandel ER, Schwartz JH, Jessell TM. Principles of Neural Science. $4^{\text {th }}$ ed. New York, US: McGraw-Hill; 2000.

6. Um HS, Kang EB, Koo JH, Kim HT. Treadmill exercise represses neuronal cell death in an aged transgenic mouse model of Alzheimer's disease. Neurosci Res. 2011;69(2):161-73. https:// doi.org/10.1016/j.neures.2010.10.004 PMid:20969897

7. van Praag $\mathrm{H}$. Neurogenesis and exercise: The past and future direction. Neuromolecular Med. 2008;10(2):128-40. http://doi. org/10.1007/s12017-008-8028-z PMid:18286389

8. Mcmorris T, Tomporowsky PD, Audiffren M. Summary and direction for future research. In: Mcmorris T, Tomporowsky PD, Audiffren M, editors. Exercise and Cognitive Function. Oxford, UK: Wiley-Blackwell; 2009. https://doi.org/10.1002/9780470740668. ch16

9. Diamond A. Effects of physical exercise on executive functions: Going beyond simply moving to moving with thought. Ann Sports Med Res. 2015;2(1):1-4. PMid:26000340

10. Pellis SM,Pellis VC. Rough-and-tumble play and the development of the social brain. Curr Dir Psychol Sci. 2007;16:95-8. https:// doi.org/10.1111/j.1467-8721.2007.00483.x

11. Morris RG, Garrud P, Rawlins JN, O'keefee J. Place navigation impaired in rats with hippocampal lesions. Nature. 1982;297(5868):681-3. https://doi.org/10.1038/297681a0 PMid:7088155

12. Billat VL, Mouisel E, Roblot N, Melki J. Inter- and intra strain variation in mouse critical running speed. J Appl Physiol. 2004;98(4):1258-63. https://doi.org/10.1152/ japplphysiol.00991.2004 PMid:15542571

13. Kania BF, Wronska D, Zieba D. Introduction of neural plasticity mechanism. J Behav Brain Sci. 2017;7:41-9. https://doi. org/10.4236/jbbs.2017.72005

14. Sekino Y, Kojima N, Shirao T. Role of actin cytoskeleton in dendritic spine morphogenesis. Neurochem Int. 2007;51(24):92-104. https://doi.org/10.1016/j.neuint.2007.04.029 PMid:17590478 
15. Koganezawa N, Hanamura K, Sekino $\mathrm{Y}$, Shirao T. The role of drebrin in dendritic spines. Mol Cell Neurosci. 2017;84:85-92. https://doi.org/10.1016/j.mcn.2017.01.004

\section{PMid:28161364}

16. Shirao T, Hanamura K, Koganezawa N, Ishizuka Y, Yamazaki H Sekino $Y$. The role of drebrin in neurons. J Neurochem. 2017;141(6):819-34. https://doi.org/10.1111/jnc.13988 PMid:28199019

17. Thomas AG, Andrea D, Bandettini PA, Berg HJ. The effects of aerobic activity on brain structure. Front Psychol. 2012;3(86):1-9. PMid:22470361

18. Macias M, Dwornik A, Skup M, Czarkowska-Bauch J Confocal visualization on the effect of shor-term locomotor exercise on BDNF and TrkB distribution in the lumbar spinal cord of the rat: The enhancement of BDNF in dendrites? Acta Neurobiol Exp. 2005;65(2):177-82. https://doi. org/10.1111/j.1460-9568.2007.05498.x PMid:15960303

19. Meeusen R, Meirleir KD. Exercise and brain neurotransmission. Sports Med. 1995;20(3):160-88.

PMid:8571000

20. Mayford M, Siegelbaum SA, Kandel ER. Synapses and memory storage. Cold Spring Harb Perspect Biol. 2012;4:1-18. https:// doi.org/10.1101/cshperspect.a005751 PMid:22496389

21. Touzani K, Puthanveettil SV, KandelER. Consolidation of learning strategies during spatial working memory task requires protein synthesis in the prefrontal cortex. PNAS. 2007;104(13):5632 37. https://doi.org/10.1073/pnas.0611554104

22. Ohno $H$, Shirato $K$, Sakurai $T$, Ogasawara J, Sumitani $Y$, Sato $\mathrm{S}$, et al. Effect of exercise on HIF-1 and VEGF signaling. J Phys Fitness Sports Med. 2012;1(1):5-16. https://doi.org/10.7600/ jpfsm.1.5

23. Radak Z, Zhao Z, Koltai E, Ohno H, Atalay M. Oxygen consumption and usage during physical exercise: The balance between oxidative stress and ROS-dependent adaptive signaling. Antioxid Redox Signal. 2013;18(10):1208-45. https:// doi.org/10.1089/ars.2011.4498 PMid:22978553

24. Gilany K, Vafakhah M. Hypoxia: A review. J Paramed Sci. 2010;1(2):43-60.

25. Ramakrishnan S, Anand V, Roy S. Vascular endothelial growth factor signaling in hypoxia and inflammation. J Neuroimmune Pharmacol. 2014;9(2):142-60. https://doi.org/10.1007/ s11481-014-9531-7 PMid:24610033

26. Prior BM, Yang HT, Terjung RL. What makes vessels grow with exercise training? J Appl Physiol. 2014;97(3):1119-28. https:// doi.org/10.1152/japplphysiol.00035.2004

PMid: 15333630

27. Sanz-Cameno P, Trapero-Marugán M, Chaparro M, Jones EA Moreno-Otero R. Angiogenesis: From chronic liver inflammation to hepatocellular carcinoma. J Oncol. 2010;2010:1-7. https:// doi.org/10.1155/2010/272170 PMid:20592752

28. Bao P, Kodra A, Canic MT, Golinko MS, Ehrlich HP, Brem H. The role of vascular endothelial growth factor in wound healing. J Surg Res. 2009;153(2):347-58. https://doi.org/10.1016/j. jss.2008.04.023

PMid:19027922

29. Van Praag $\mathrm{H}$. Exercise and the brain, something to chew on Trends Neurosci. 2009;32(5):283-90.

PMid:19349082

30. Lopez CL, Leroith D, Aleman IT. Insulin-like growth factor 1 is required for vessel remodeling in the adult brain. PNAS. 2004;101(26):9833-8. https://doi.org/10.1073/ pnas.0400337101

31. Bullitt E, Rahman FN, Smith JK, Kim E, Zeng D, Katz LM, et al. The effect of exercise on the cerebral vasculature of healthy aged subjects as visualized by MR angiography. Am J Neuroradiol. 2009;30(10):1857-63. https://doi.org/10.3174/ajnr. a1695

PMid:19589885

32. Sun $Y$, Jin K, Mao Xo, Zhu Y, Greeberg DA. Neuroglobin is upregulated by and protects neurons from hypoxic ischemic injury. PNAS. 2001;98(26):15306-11. https://doi.org/10.1073/ pnas. 251466698

PMid:11742077

33. Yoon J, Seo Y, Kim J, Lee I. Hippocampus is required for paired associate memory with neither delay nor trial uniqueness. Learn Mem. 2012;19(1):1-8. https://doi.org/10.1101//m.024554.111 PMid:22174309

34. Raychaudhuri S, Skommer J, Henty K, Birch N, Brittain T. Neuroglobin protects nerve cells from apoptosis by inhibiting the intrinsic pathway of cell death. Apoptosis. 2010;15(4):40111. https://doi.org/10.1007/s10495-009-0436-5 PMid:20091232

35. Kirk-Sanchez NJ, Mcgough EL. Physical exercise and cognitive performance in the elderly: Current perspectives. Clin Interv Aging. 2014;9:51-62. https://doi.org/10.2147/cia.s39506 PMid:24379659

36. Fediani Y, Dewi MR, Irfannuddin I, Saleh MI, Dhaini S. The effect of regular aerobic exercise on urinary brain-derived neurotrophic factor in children. Paediatr Indones. 2014;54(6):351-7. https:// doi.org/10.14238/pi54.6.2014.351-7 